\title{
Review on Zoonotic Bacterial Diseases of Fish
}

\author{
Wondimu Wodajo* \\ Sodo Regional Veterinary Laboratory, \\ Ethiopia \\ *Corresponding Author: Wondimu Wodajo, Sodo Regional Veterinary Laboratory, Email: tinbetw@gmail.com
}

\begin{abstract}
Zoonosis refers to a disease that can be transferred from animals, whether wild or domesticated, to humans. With the global growth of aquaculture and the increasing volume of international trade in live aquatic animals and their products zoonoses require special attention. The interaction of pathogens between humans and aquatic species is complex because of the various routes of transmission coupled with the fact that many of the zoonotic pathogens do not cause disease in aquatic organisms. Zoonotic infections can be divided into: a) topically acquired infections, caused by contact with aquatic animals or their products $b$ ) foodborne infections, caused by the ingestion of raw or undercooked aquatic products. Pathogens may be indigenous to the aquatic environment or occur as the result of environmental contamination, due to, for example, farms being located in polluted areas, the use of excreta as fertiliser and faecal effluents from human sewage, animal farms or wild animals (Salmonella, Shigella, pathogenic Escherichia coli, Yersinia, Brucella, Edwardsiella). Pathogenic and potentially pathogenic bacteria associated with fish and shellfish include mycobacteria, Streptococcus iniae, Vibrio vulnificus, Vibriospp., aeromonads, Salmonella spp. and others. From the standpoint of microbiology, fish and related products are a risk foodstuff group. Particularly Clostridium botulinum type E and Vibrio parahaemolyticus rank among pathogenic bacteria associated with fish. Other potentially pathogenic bacteria associated with fish and shellfish include $C$. perfringens, Staph. spp., Salm. spp., Shigella spp.,V. cholera and other vibrios. People with compromised immune systems should avoid handling fish or cleaning fish tanks. They should wear heavy, waterproof gloves when handling or processing fish, and cleaning home aquariums or fish tanks. Therefore, there is a need for detail epidemiological surveillance of zoonotic bacteria in fish and its public health significances.
\end{abstract}

Keywords: Aeromonas; Contact; C.Perfringens; Foodborne; Zoonotic; Mycobacteria; Vibro Spp.

\section{INTRODUCTION}

Zoonosis refers to a disease that can be transferred from animals, whether wild or domesticated, to humans. With the global growth of aquaculture and the increasing volume of international trade in live aquatic animals and their products (FAO, 2012), zoonoses require special attention. The increasing interface between humans and aquatic animals which may harbour infectious agents is a potential public health concern. Despite an increased awareness of zoonotic disease agents, their diagnosis in humans by clinicians and medical practitioners is often hampered by a poor knowledge of the zoonotic potential of disease agents in aquatic species and the associated clinical signs (Evans et al., 2009). In addition, the interaction between diseased aquatic animals and humans in those occupational contexts may increase the flow of pathogens between aquatic animals and humans and contribute to the increased occurrence zoonotic disease.

Fish medicine has been a relatively small discipline of veterinary attention in the past because of many factors, the most important of which is the perceived value of pet and ornamental fish. As more people invest in expensive species, such as koi and various reef species, the demand to provide a higher level of care for these animals is increasing. This trend is also evident in the commercial food and bait fish industry, where aquaculture producers are expecting improved standards of care for populations of fish that are worth millions of dollars. With increasing numbers of pet and production fish operations, veterinarians will be expected to have the abilities and knowledge to diagnose and treat aquatic species and provide a standard of care commensurate with other commonly treated animal species (Toby and Stephen, 2007). 
Human infections caused by pathogens transmitted from fish or the aquatic environment are quite common depending on the season, patients' contact with fish and related environment, dietary habits and the immune system status of the exposed individual. They are often bacterial species facultatively pathogenic for both fish and man and may be isolated from fish without apparent symptoms of disease. The infection source may be fish kept either for food or as a hobby (Acha and Szyfres, 2003).Thorough anamnesis and microbiological examination are the prerequisites for correct diagnosis. However, quantification of the occurrence of these diseases is difficult because many cases, typically gastrointestinal illness, go unreported; the symptoms usually do not last long and are self-limiting in healthy people (Novotny et al., 2004).

As their caseloads of aquatic species increase, veterinarians will come into contact with zoonotic diseases specific to aquatic species that have been of little concern when dealing with terrestrial animals. Certain pathogens pose a specific potential threat to veterinarians, pet owners, and producers working with finfish species. Although there is an extensive list of pathogens that are communicable to humans from aquatic species via consumption, pathogens can also be encountered during examination, handling, and treatment of aquatic species. It is important for veterinarians to be aware of the clinical signs that are associated with these specific zoonoses and ways to minimize risk of exposure to the causative organisms (Toby and Stephen, 2007).

Potential biological contamination of aquaculture products can occur from bacteria, viruses, parasites and biotoxins (Huss et al., 2003). The location of the farm, the species being farmed, water temperature, husbandry systems, postharvest processing, and habits in food preparation and consumption are among the main factors influencing the risk associated with aquatic animals and their products. Zoonotic infections can be divided into: a) topically acquired infections, caused by contact with aquatic animals or their products b) foodborne infections, caused by the ingestion of raw or undercooked aquatic products. Pathogens may be indigenous to the aquatic environment or occur as the result of environmental contamination, due to, for example, farms being located in polluted areas, the use of excreta as fertiliser and faecal effluents from human sewage, animal farms or wild animals
(Salmonella, Shigella, pathogenic Escherichia coli, Yersinia, Brucella, Edwardsiella) (Haenen et al., 2013). Pathogenic and potentially pathogenic bacteria associated with fish and shellfish include mycobacteria, Streptococcus iniae, Vibrio vulnificus, Vibriospp., aeromonads, Salmonella spp. and others (Chattopadhyay, 2000).

It can be extremely difficult to detect certain invitro slow growing causative agents of diseases such as those of mycobacterial infections or infections caused by anaerobic pathogens. Mycobacterial infections are quite often misdiagnosed with subsequent inappropriate therapy. Consequently, the disease can last for years (Ang et al., 2000). Therefore, the objective of this seminar paper are to elaborate an overview of significant zoonotic bacterial diseases of fish transmitted from fish used as food or by handling them, their pathogens, prevention and control, public health significance and economic impact.

\section{LiTERATURE REVIEW}

\subsection{Epidemiology}

\subsubsection{Source and Route of Transmission of Zoonotic Bacterial Fish Diseases}

The interaction of pathogens between humans and aquatic species is complex because of the various routes of transmission coupled with the fact that many of the zoonotic pathogens do not cause disease in aquatic organisms. Thus, as unaffected carriers, seemingly healthy fish have the potential to transmit pathogens to humans. It is also possible for commensal organisms that typically cause few problems for aquatic species to become a zoonotic pathogen of humans. As a further complication associated with pathogen diagnosis in fish, many clinical signs of the disease in aquatic species have little relevance to the clinical signs that develop in affected humans (Toby and Stephen, 2007).

Humans might acquire zoonotic bacteria via ingestion of contaminated seafood or water, or through direct topical contact via stings, bites, spine/pincer injuries, or through open wounds on the handler. Individuals frequently exposed to fish, their products, or their environment (for example fishermen or fish-processing workers), are at higher risk. Humans with immune compromised health status may be at greater risk. Dietary choices, such as live and fresh seafood, and seasonality (i.e., due to higher Vibrio levels in warmer water) are consistent 
risk factors for seafood-related illness in humans (Iwamoto et al., 2010).

Groups most at risk of topically acquiring zoonotic bacteria from fish include aquaculture professionals; fish culturists, processors, and handlers; and commercial and recreational fishermen and fisherwomen. They routinely have direct skin contact with fish, often in humid indoor facilities and at temperatures close to the optimal growth conditions for bacteria. Individuals who are immune compromised and have open skin injuries and/or are pierced by fish spines, are at risk of developing a zoonotic infection. It can be inferred that immunocompromised visitors to wellness centres are at risk from this practice (Haenen et al., 2013).

Most of the bacterial causes of diarrhea are zoonotic. Vibrio vulnificus and motile Aeromonas can also cause bloodstream infections, especially in immunocompromised individuals, while Clostridium botulinum and Listeria can cause more severe diseases (Ravel et al., 2009). Among the 4093 foodborne disease outbreaks reported globally from 1988 to $2007,277(6.8 \%)$ were attributable to seafood, primarily due to Vibrio spp. and $C$. botulinum. In Canada, 20 seafood-related outbreaks were reported from 1996 to 2005, mostly due to Salmonella enteric (25\%), C. botulinum (15\%), Campylobacter spp. (10\%), and Staphylococcus aureus (10\%) (Ravel et al., 2009).

Data on the prevalence and incidence of topically acquired zoonotic infections from fish are scarce, as many are not reported or diagnosed. In addition, cases of human infection with these bacteria are not usually notifiable. Vibrio vulnificus infection in humans is notifiable in the United States (USA), and is currently being considered for possible notification in the Netherlands. A 2009 workshop held on zoonotic infections from fish and shellfish identified the need to analyse the current literature and promote more systematic reviews of the available evidence (Haenen et al., 2013).

\subsection{Zoonotic Bacterial Pathogens of Fish Transmitted by Contact with Fish Living in Wild and Fish in Aquaculture}

\subsubsection{Vibrio Vulnificus}

Vibrio vulnificus is a gram-negative bacterium which comprises two biotypes. Biotype 1 is an opportunistic human pathogen. Biotype 2 was considered an obligate eel pathogen but it is also an opportunistic pathogen for humans and can be transmitted by water. The risk factors for severe $V$. vulnificus infections are chronic hepatic disease or immunodeficiency in patients (Osawa et al., 2002).

Vibrio vulnificus is a microorganism that is frequently found in warm coastal waters. It has been isolated from seawater, sediments, plankton and shellfish (oysters, clams, crabs) in the Gulf of Mexico and off the Atlantic and Pacific coasts of the USA. The prevalence of pathogenic vibrios in waters depends on environmental factors, such as water temperature, salinity and phytoplankton concentration. The presence of Vibrio spp. has also been reported in Europe, where levels are generally low, except in bivalves (Normanno et al., 2006).

Primary septicaemia or the gastrointestinal illness in human beings may follow after ingesting raw seafood, particularly of ocean filter feeders (e.g. oysters and clams) and fish infected by $V$. vulnificus. For susceptible person's septicaemia is associated with a mortality rate greater than $50 \%$ and maybe characterized by fevers, chills, and skin lesions like blisters, swelling, and purpuras (Osawa et al., 2002). Wound infections are seen after injury to the skin in a marine environment or from the exposure of pre-existing wounds to seawater (Borenstein and Kerdel, 2003).

The species vulnificus has been subtyped into three biotypes, with serovars: biotype 1 in crustaceans and humans, biotype 2 in eels, among others, and biotype 3 in tilapia. A polymerase chain reaction was developed to subtype biotype 2 into potential zoonotic strains (serovar E). Biotyping is no longer considered accurate for subtyping. Current subtyping is based on sequence data, which showed that biotype 2 strains were polyphyletic. Biotype 2 was thought to be a pathovar, i.e. one of a set of strains of $V$. vulnificus with the pathogenic potential to infect fish and cause vibriosis (Osawa et al., 2002).

In humans, Vibrio vulnificus infection is the most common fish-derived Vibrio infection, and the major route of exposure has been reported to be through puncture wounds and ingestion (Haenen et al., 2013). Clinical signs of such infections in humans are necrotizing fasciitis, edema, and swelling in the immediate area of the puncture wound. Septicemia after ingestion of $V$ vulnificus (typically in shellfish) results in 
death in $50 \%$ to $60 \%$ of clinically affected humans (Oliver, 2005).

In aquaculture and in the wild, $V$. vulnificus is known to cause disease and is a serious pathogen of Japanese eels and European eels. Affected eels show extensive haemorrhages and severe necrosis. Clinical signs include haemorrhaging on the body surface, and in the gastrointestinal tract, gills, heart, liver and spleen. Since1991, the bacterium has been isolated 23 times from indoor cultured eels with deep ulcers and high mortality in the Netherlands (Austin and Austin, 2007).

Vibrio vulnificus is a zoonotic invasive pathogen. In low numbers, it causes primary wound infections when a skin injury comes into contact with infected seawater, fish or shellfish, which may develop into fasciitis necroticans and even full sepsis and death. Immunocompromised patients suffering from liver diseases are at risk. Mortality after wound infections may reach 25\%. After sepsis, mortality may reach up to $55 \%$, mostly within $48 \mathrm{~h}$ of the first appearance of clinical signs (Chiang and Chuang, 2003). Most human cases are from biotype 1; however, since 1993, biotype 2 has also been reported as a cause of human disease, with some severe cases of fasciitis necroticans and sepsis in patients. Biotype 3 is a rather new type which has caused wound infections after slaughtering tilapia in Israel (Austin et al., 2005).

\subsubsection{Alginolyticus}

Vibrio alginolyticus is a gram-negative marine bacterium. It is medically important since it causes otitis and wound infection. It is also present in the bodies of animals such as pufferfish, where it is responsible for the production of the potent neurotoxin, tetrodotoxin (Reilly et al., 2011).

$V$. alginolyticus was first identified as a pathogen of humans in 1973. It occasionally causes eye, ear, and wound infections. It is a highly salt-tolerant species and can grow in salt concentrations of $10 \%$. Most clinical isolates come from super infected wounds that become contaminated at the beach (Longo et al, 2011).

It was described as the cause of otitis media in a child handling pressure-equalizing tubes. Infection with $V$. alginolyticus can occur even after mild, brief exposure to seawater. The interval between exposure to seawater and the onset of clinical infection can be prolonged (Feingold and Kumar, 2004). Tetracycline usually results in cure. V. alginolyticus is rare cause of bacteremia in immune compromised hosts (Longo et al, 2011).

\subsubsection{Edwardsiella Tarda}

Edwardsiella tarda produces the disease commonly known as 'fish gangrene', 'emphysematous putrefactive disease of cat fish' or 'red disease of eels' and referred to as Edwardsiella septicaemia (ES), a systemic disease (Hannen et al., 2013).

Edwardsiella tarda infection in catfish has been termed emphysematous putrefactive disease. In fish, this infection induces nonspecific clinical signs that may include petechiae and ulcerations of the skin and excessive mucus production. The disease can progress, and fish may develop large gas-filled abscesses that appear as raised areas of skin. As a result of lesions that destroy muscle tissue, catfish in advanced stages of disease are often unable to swim. Humans infected with $E$ tarda via a wound or ingestion may develop necrotic skin lesions and gastroenteritis. Infections with any of these bacteria can remain localized at the point of entry or can become systemic and result in severe cases of meningitis (Toby and Stephen, 2007).

Human infections caused by $E d w$. tarda are considered rare and have only occasionally been described outside tropical or subtropical areas. Risk factors that are associated with $E d w$. tarda infections include in addition to contact with exotic animals (reptiles or amphibian) or pre existing liver disease exposure to aquatic environments and dietary habits (raw fish ingestion). Infections associated with this species include bacterial gastroenteritis, wound infections (cellulitis or gas gangrene), and systemic diseases such as septicaemia, meningitis, cholecystitis, and osteomyelitis (Noga, 2010). Septic arthritis of the knee caused by $E d w$. tarda after a catfish puncture wound was described by Ashford et al. (1998). Protracted diarrhoea in a 2-month old Belgian infant was associated with $E d w$. tarda as the only potential pathogen. The same organism was isolated from a tropical aquarium fish in the home of the patient (Novotny et al., 2004).

\subsubsection{Streptococcus Iniae}

Streptococcus iniae, a Gram-positive bacterium, is a zoonotic pathogen in fresh water and marine fish, causing disease outbreaks in aquatic 
species and invasive disease in humans. This pathogen causes significant economic losses, particularly in the tilapia and hybrid striped bass aquaculture industries in the USA, Japan, Israel, South Africa, Australia, and the Philippines, Taiwan, Bahrain and other countries ((Baiano and Barnes, 2009).

St. iniae causes meningoencephalitis and death in cultured fish species but may also be an emerging human pathogen associated with injury while preparing fresh aqua cultured fish. Between 1995 and 1996 four cases of bacteraemia infections were identified among patients at a hospital in Ontario. Three were accompanied by cellulitis and the fourth with infective endocarditis, meningitis, and probable septic arthritis. St. iniae was isolated from all four patients and the cases were associated with previous injury during preparation of fresh, whole fish (Novotny et al., 2004).

Topically acquired St. iniae infections have been reported from 26 patients in five countries: Canada, Hong Kong, Singapore, Taiwan and the USA. Most of the affected individuals were Asian (85\%) and ranged in age from 40 to 88 years. Clinical signs included cellulitis, septicaemia, endocarditis, arthritis, meningitis, osteomyelitis, fever and abdominal distension and pneumonia. Fifty-eight percent of the patients were known to have handled or been exposed to fresh fish. Underlying conditions included chronic rheumatic heart disease, osteoarthritis, hypertrophic obstructive cardiomyopathy, duodenal ulcer and gallstones, diabetes mellitus, hepatitis C-related liver cirrhosis, alcoholism, hypertension, hypothyroidism and partial mastectomy; they were reported in $35 \%$ of those contracting St. iniae infections (Evans et al., 2009).

\subsubsection{Mycobacterium Species}

Mycobacteriosis is particularly significant among infections transmissible from fish to human beings. Mycobacteriosis of fish is a chronic progressive disease spread all over the world. The most frequently detected mycobacterial species were the following: Mycobacteriummarinum, M. fortuitum and $M$. chelonae. M. avium,M. gordonae, M. abscesus, M. aurum, M. parafortuitum, $M$. poriferae, and M. triplex have also been isolated from fish (Diamant et al., 2000).

Mycobacteriosis of aquarium fish in the Czech Republic is one of the most commonly diagnosed bacterial diseases (Novotny et al.,
2004). Gross changes may include emaciation, ascites, exophthalmos, and keratitis, changes in pigmentation and skin ulcerations. The significance of fish mycobacteriosis as zoonosis is evident from case reports published in scientific papers. Fish have been convincing sources of many cases of mycobacteriosis diagnosed abroad. Ninety-nine publications dealing with the infection of 652 cases of human beings with $M$. marinum appeared between 1966 and 1996. Of 193 infections with known exposures, $49 \%$ were associated with aquarium environment, $27 \%$ with injury by aquarium fish and $9 \%$ with injury during bathing in sea or brackish water (Jernigan and Farr, 2000).

$M$. marinum often infects home aquarium hobbyists. With the expansion of aquaculture and popularity of recreational fishing in Australia, medical practitioners can expect to see more infections of this nature. Diagnosis and treatment may be difficult, especially in view of emerging antibiotic resistance in fish pathogens (Lehane and Rawlin, 2000).

Mycobacterium marinum is an acid-fast rodshaped bacterium that causes worldwide chronic and severe disease in many fish species in fresh water and brackish and marine waters. At least 167 species from more than 40 families of fish are susceptible to Mycobacterium species. In fish, $M$. marinum causes chronic systemic disease, with granulomas in multiple organs and tissues, loss of scales, loss of appetite, discoloration, apathy, exophthalmus, slimeless skin, ulcers and eroded fins, followed by death (Gauthier and Rhodes, 2009). Mycobacterium marinum has an optimum growth temperature of $30^{\circ} \mathrm{C}$, and does not grow well at $37^{\circ} \mathrm{C}$ (Jacobs et al., 2009).

Mycobacteriosis is particularly significant among infections transmissible from fish to human beings. Mycobacteriosis of fish is a chronic progressive disease spread all over the world. Misdiagnosis and delayed treatment of M. marinum infection are common because of its diverse manifestations. The Centers for Disease Control and Prevention (CDC) in the USA included $M$. marinum on their list of 'Emerging infectious diseases' from 2008. Additional topically acquired Mycobacterium spp. with zoonotic potential include: $M$. chelonae, $M$. fortuitum, $M$. abscessus, $M$. interjectum, $M$. scrofulaceum, $M$. szulgai, $M$. similae and M. triplex (Haenen et al., 2013) 


\subsection{Food Borne Zoonotic Bacterial Pathogens Associated with Fish and Fish Products}

From the standpoint of microbiology, fish and related products are a risk foodstuff group. Particularly Clostridium botulinum type E and Vibrio parahaemolyticus rank among pathogenic bacteria associated with fish. Other potentially pathogenic bacteria associated with fish and shellfish include $C$. perfringens, Salm. spp., Shigella spp., V. cholera and other vibrios. Outbreaks usually occur due to the ingestion of insufficiently heat-treated fish or products contaminated after/during their processing. Freezing fish and related products in the seawater, intensive handling, long-time transport or cooking in fishing containers straight on the deck contributes to their contamination with microorganisms (Novotny et al., 2004.

Microbiological criteria, including samples plans and methods of analysis, are laid down when there is a need to protect public health. Microbiological criteria for fish and fishery products include quantification of the counts of Escherichia coli, thermo tolerant coliform, mesophilic aerobic bacteria and pathogenic $V$. parahaemolyticus is performed during the production. At the finished product stage, the measure monitored is the quantification of the count of S. aureus and detection of bacteria of Salmonella genus as their presence indicates recontamination of a finished product (Council Directive91/493/EEC).

Aeromonas spp compose a large portion of the bacterial flora among freshwater aquatic organisms that are maintained in a wide range of water temperatures. Aeromonas organisms are gram-negative, motile, facultative anaerobic rods that are ubiquitous in the aquatic and terrestrial environments. Aeromonas hydrophila, Aeromonas caviae, Aeromonas sobria, and Aeromonas schubertii have all been implicated in human disease and are found in association with aquatic finfish and crustaceans (Toby and Stephen, 2007).

These aeromonads frequently cause disease in cultured and pet fish. Clinical signs of Aeromonas infections in fish are seldom specific and include ulcerative lesions of the skin around the base of the fins and anus, raised scales, abdominal distension, and exophthalmia, all of which are signs that commonly develop with other bacterial infections. Depending on the severity of infection, anemia, hepatomegaly, and ascites may develop in affected fish (Yousr et al., 2007).

Aeromonad infections in fish are often secondary to other stressors such as a suboptimal environment, poor water quality, parasitism, and nutritional deficiencies. The primary route for transmission to a clinician or persons handling fish is contact with mucus and tissues from infected or carrier fish. Cuts and abrasions that are already present on the hands of the handler, as well as wounds caused by handling fish directly, are possible routes of infection. Human infections with Aeromonas spp often develop in immunocompromised persons for whom the bacteremia can prove life threatening (Nemetz and Shotts, 1993). In healthy individuals, the most common signs of an Aeromonas spp infection include localized wound swelling and gastroenteritis (Toby and Stephen, 2007).

Aeromonads (A. hydrophila, A. sobria, and A. salmonicida) can be causative agents not only of human enteritis but also of a fatal septicaemia as recorded in a 15-year old healthy girl; the causative agent was A. sobria (Shiina et al., 2004). Aeromonads septicaemia most often caused by A. hydrophila, was described as a complication in 50 patients with liver cirrhosis and eye infection in immuno-compromised patients. Fatal bacterial pneumonia in a 5-year old child was also caused by A. hydrophila. A. salmonicida is the causative agent of the fish disease called furunculosis but human disease has not been described (Qu et al., 2003)

$V$. parahaemolyticus has been isolated from sea and estuary waters on all continents with elevated seawater temperatures. The agent's distribution shows marked seasonal variations in natural reservoirs. During cold months, it is found in marine sediment; during warm months, it is found in coastal waters, fish, and shellfish. There have been a few reports of the isolation of $V$. parahaemolyticus from continental waters and fish in rivers or lakes. V. parahaemolyticus is frequently isolated from fish, molluscs, and crustaceans throughout the year in tropical climates and during the summer months in cold or temperate climates. $V$. parahaemolyticus generally causes acute gastroenteritis that is self-limiting; however, several cases require hospitalization and, on rare occasions, septicaemia may occur. Fish food associated with illnesses due to consumption of $V$. parahaemolyticus includes fish-balls, fried mackerel (Scomber scombrus), tuna (Thunnus 
thynnus), and sardines (Sardinapilchardus). These products include both raw or undercooked fish products and cooked products that have been substantially recontaminated (Baffone et al., 2000).

Of the bacteria that may be encountered when handling fish during an examination, several species are not generally considered transmissible through contact but rather through ingestion. These bacteria would be less likely to cause infection via the oral route of transmission in a clinical setting, but are included to provide more complete information regarding fish-borne bacteria. They are almost all ubiquitous in the environment, can be cultured from numerous sources, and are not considered specific to aquatic environments or fish. Staphylococcus spp are gram-positive cocci that cause disease in many species of animals. However, in fish, this bacterium is rarely a primary cause of disease, but can be cultured from samples of aquarium and pond water. The greatest source for illness associated with Staphylococcus spp is ingestion of enterotoxin produced by the bacteria during improper food handling and preparation. Clostridium spp (gram-positive rods) contribute to the resident intestinal bacteria in many fish species and rarely cause disease in fish (Toby and Stephen, 2007).

Compared with the effects of toxins from other Clostridium spp, Clostridium botulinum toxins can have effects that are much more severe, including generalized muscle paralysis that may result in death from respiratory system collapse. Plesiomonas shigelloides is a gram-negative bacterium that is not specific for aquatic species but is widely distributed in water and soil in temperate and tropical regions. This organism causes disease in humans generally through ingestion of improperly cooked sea foods. Human disease caused by $P$ shigelloides is characterized by 3 forms of gastroenteritis: secretory, invasive, and cholera-like. Occupations that are reported to be at high risk for this infection are fish handlers, aqua culturists, veterinarians, zookeepers, and water sports performers (Senanayake et al., 2004).

C. perfringens, an important cause of both food poisoning and non-food-borne diarrhoeas in humans, was found in a number of fish owing to contamination with sewage, which is the main source of this organism (Chattopadhyay, 2000). C. perfringens was isolated from 37 faecal samples $(38.9 \%)$ of cod. All isolates were $C$. perfringens toxin type $\mathrm{A}$; the gene encoding for beta 2 toxin was found in isolates from two cods (2.1\%) (Aschfalk and Muller, 2002).

Campylobacter spp are gram-negative rods that are associated with water contaminated with fecal material. Low numbers of infections in relation to shellfish consumption have been reported. Salmonella spp (also gram-negative rods) have commonly been isolated from contaminated aquarium and tanks and polluted ponds and salt water. Salmonella spp are not known to be pathogenic to fish but can be associated with human disease (Senanayake $e t$ al., 2004).

\subsection{Diagnosis of Zoonotic Bacterial Pathogens of Fish}

Samples that are obtained from fish for diagnostic purposes are frequently sent to laboratories outside of veterinary clinics and need to be collected and shipped properly (Toby and Stephen, 2007). Techniques for collection of samples from aquatic animals are the same as techniques for collection of samples from mammals' aseptic collection procedures are required to ensure appropriate and representative results of diagnostic testing. Most bacterial pathogens can be cultured from samples of the caudal kidney of a fish, and this is the most common sample submitted (Ho et al., 2006).

Bacterial colonies grown on the agar plate should be checked for morphology, and bacteria examined for motility, staining affinity, biochemical reactions and sometimes, immunological properties. All testing is performed on 24 to 48 -hour-old colonies. For presumptive identification, pure bacterial colonies should be gram stained and initially tested for motility, sensitivity to vibriostat $(0 / 129)$, oxidase activity, and the oxidationfermentation (O-F) test applied (Snježana and Vladimir, 2017).

Gram staining of a smear on a glass slide is a basic test for general medical bacteriology. Most fish-pathogenic bacteria are Gram negative. Motility testing determines their capability of independent movement. A single bacterial colony is suspended in a drop of saline, covered by a coverslip and motility is observed using a compound microscope. The movement should not be confused with Brownian movement, which is a random and non-directional vibration exhibited by all bacteria. The oxidase test demonstrates the presence of cytochrome oxydase $\mathrm{C}$, an enzyme situated in the bacterial 
membrane and involved in the respiratory electron transport chain of bacteria (Midlyng et al., 2010).

A commercially available oxidase strip shows a colour change to purple if a cytochrome oxydase $\mathrm{C}$-positive colony is applied. The O-F test is performed to determine if a bacterium is metabolizing glucose and if it does, whether this is done by oxidation (aerobic conditions) or fermentation (anaerobic conditions). Vibriostat testing is carried out using the chemical 0/129, which inhibits the growth of most bacteria belonging to the genus Vibrio. All mentioned tests should be performed to achieve a preliminary identification (Snježana and Vladimir, 2017).

Definitive determination of the bacterial species is done using flowcharts detailing biochemical tests. There are several commercially available diagnostic kits such as the BBL ${ }^{\mathrm{TM}}$ Crystal $^{\mathrm{TM}}$ Identification Systems (the identification method uses fluorogenic and chromogenic reagents and following an incubation period, the sample can be manually read on the Crystal ${ }^{\mathrm{TM}}$ panel viewer to obtain a profile number) or the Analytical Profile Index (API) system, a wellestablished method for manual microorganism identification to species level that is based on extensive databases. The kits include strips that contain up to 20 miniature biochemical tests (Plumb and Hanson (2011).

However, some bacterial pathogens may be better isolated from other tissues; $S$ inae, for example, is cultured most successfully from specimens of brain tissue. The veterinary clinician and diagnostic laboratory should also be aware that most fish pathogens should be cultured from specimens at room temperature $\left(20^{\circ}\right.$ to $22^{\circ} \mathrm{C}\left[68.0^{\circ}\right.$ to $\left.\left.71.6^{\circ} \mathrm{F}\right]\right)$ rather than at the typical bacterial culture temperature for mammalian specimens of $37^{\circ} \mathrm{C}\left(98.6^{\circ} \mathrm{F}\right.$ ) (Toby and Stephen, 2007).

Fish samples aseptically dissected to collect internal tissues samples (i.e. kidney, liver and spleen) for bacteriology using the Blue Book (2010). Sterile bacteriological swabs were inoculated on brain heart infusion (BHI) media and incubated at $26-28 \mathrm{f} \mathrm{C}$ for $24-48 \mathrm{~h}$. Pure cultures were obtained from colonies with identical morphology, then restreaked on BHI media. All isolates were kept in BHI broth with $30 \%$ glycerol at" $80{ }^{\circ} \mathrm{C}$. Swabs were also done around necrotic areas of sick fish and inoculated on Hsu-shots media (with Tobramycin); which is a selective media for columnaris disease. Pure isolates were analysed morphologically, biochemically and physiologically following Blue Book (2010), and Plumb and Hanson (2011).

Nucleic acid amplification is a valuable tool for diagnosis of aquatic animal diseases. Several amplification methods are available: PCR (which can be performed as a single or nested assay), reverse transcription PCR (RT-PCR), multiplex PCR and quantitative or real time PCR. PCR is used to amplify certain regions of DNA. Short oligonucleotide primers are designed that will hybridize to each end of the target region of DNA to be amplified, on opposite strands of the DNA (Midlyng et al., 2010).

\subsection{Prevention and Control Measures}

Aquatic medicine is similar to other areas of veterinary medicine in that prevention is a much more economical and effective way of avoiding zoonotic diseases than response to existing infections. Thus, discussion of biosecurity principles with clients and implementation of an appropriate biosecurity plan for aquaculture facilities are paramount to diminishing the introduction and minimizing the spread of a pathogen in an animal population (Toby and Stephen, 2007).

The control of fish diseases is difficult because fish are cultured in a system where production is dependent on natural environmental condition. Deterioration in the aquatic environment cause the occurrence of most fish diseases and also environmental effects play a great role in influencing the health status of fish. Therefore, the multidisciplinary approaches involving the characteristics of potential pathogenic microorganisms for fish, aspects of the biology of fish as well as a better understanding of the environmental factors will allow the application of adequate measures to prevent and control the diseases limiting fish production (Toranzo et al., 2005).

Zoonotic infections originating in aquatic animals are under-reported, making risk analysis difficult. To reduce the risks of topically acquired infection, people should avoid direct contact with potentially contaminated fresh or salt water if they have open cuts, scrapes or sores on their skin (Haenen et al., 2013).

People with compromised immune systems should avoid handling fish or cleaning fish tanks. They should wear heavy, waterproof gloves when handling or processing fish, and 
cleaning home aquariums or fish tanks. Everyone should wash their hands thoroughly with soap and water after contact with fish or processing fish. It is also important to ensure the regular and adequate chlorination of swimming pools and fish tanks to kill any bacteria that may be present (Evans et al., 2013).

There are several measures that can be recommended by veterinarians to clients for reduction of the risk of zoonotic pathogen introduction into established aquatic animal populations. One is to establish a quarantine area or tanks that are separate from existing populations in which new fish can be held. This is helpful in preventing zoonotic pathogens and also other disease agents (i.e, viral, bacterial, parasitic, and fungal) from entering the clients' fish populations (Jahnck and Schwar, 2002).

Typically, new fish should be held in quarantine for 30 to 45 days to allow observation of behavior, feeding response, and development of any clinical signs. This period is generally sufficient to detect the presence of most active pathogens in newly acquired fish, although chronic infections with pathogens such as Mycobacterium spp may not be evident. The quarantine area or facility should be treated as a separate area and should be equipped with nets, feed, water supply, and tank-cleaning supplies designated for use solely in that area to prevent contamination of existing populations of fish (Toby and Stephen, 2007).

\subsection{Treatment}

Edwardsiella tarda occurs sporadically in aquaculture animals and humans. Extraintestinal infections caused by puncture wounds are susceptible to gentamycin, amoxicillin, trimethoprim-sulfamethoxazole, cephalosporins and oxyquinolones. As with other fish-derived zoonotic bacteria, culture at lower temperatures is required (Lehane and Rawlin, 2000). Systemic antibiotic treatments, improvement of water quality, stress reduction are treatment options (Savan et al., 2004).

Antibiotics are necessary to treat $V$. vulnificus infections. Effective antibiotics include tetracycline, third-generation cephalosporins (e.g. ceftazidime), and imipenem, from the carbapenem class (these are typically restricted in use to avoid widespread bacterial resistance). In cases of wound infection, aggressive debridement is necessary to remove the necrotic tissue (Todar, 2008).

\subsection{Public Health Importance}

Food-borne zoonoses are an important public health concern worldwide and every year a large number of people affected by diseases due to contaminated animal originated food consumption (Leon and Kaya, 2014).

Fish pathogenic bacteria often produce devastating infections in fish farms where dense populations of fish are intensively reared. Bacterial infections in fish are regularly treated with antibiotics in medicated feed. So far, most of the fish pathogenic bacteria with a history in diseased fish farms have developed drug resistance. Modern fish farming relies increasingly on vaccination procedures and improved management to avoid infections (Bowden et al., 2003). For example, the Norwegian aquaculture industry has produced over one million tons farmed fish by using improved vaccines, management techniques, and only $649 \mathrm{~kg}$ of antimicrobials in 2011 (NORM/NORM-VET, 2010).

In Ethiopia, both pathogenic and nonpathogenic bacteria can be isolated from different parts of fish, among pathogenic bacteria zoonosis Edwardsiella tarda has been isolated from apparently healthy fish of Lake Ziway and Tana. The practice of consuming partially cooked fish meals, manual handling of fish and unhygienic practice during filleting would expose the public to higher risk of contracting the disease (Nuru, 2007).

Even though, there is very good understanding on bacterial diseases are the main cause of high mortalities and economic losses fishes and fish farms and bacteria zoonosis in worldwide, in Ethiopia information is scant and inadequate except for few types of researches which have not been well documented. As far as the knowledge of researchers considered, there were no any research have been conducted in Lake Hayiq (Lugo) (Tsfaye et al., 2018).

In Ethiopia, even though limited work is there on investigation of prevalence of $S$. aureus in fish and fish products, the available data indicated that the prevalence is very high which was $65 \%$ as reported by Teka et al. (2017) in frozen raw fillet collected from Lakes Abaya and Chamo. This could also show that $S$. aureus can survive freezing temperature and pose threat to public health (Mekonnen et al., 2019). 
Some authors indicated public health significance of consumption of fresh fish contaminated with especially A. hydrophila for sensitive populations, such as children, elderly persons and immunocompromised people (Kebede and Habtamu, 2016). It can develop in refrigeration temperatures and are responsible for food and waterborne diseases that can cause a range of human diseases that vary in severity from a self-limiting gastroenteritis to potentially fatal septicemia (Niamah, 2012).

\subsection{Economic Impact}

Fresh-water cultured fish as well as marine fish are devastated by bacterial diseases, including tilapia, cat fish, carp, trout, salmon, bass, perch, sturgeon and eel. The annual economic loss associated with three bacterial fish pathogens (Aeromonas hydrophila, Yersinia ruckeri and Vibrio fluvialis) between 1990 and 1992 in China was estimated at more than $\$ 120$ million. Since the value of aquaculture production was estimated at $\$ 105.3$ billion in 2009, the global economic impact of bacterial diseases on aquaculture production would be within the range of hundreds of millions to billions of dollars annually (Wei, 2002).

Bacterial diseases are considered the main cause of high mortalities and economic losses in fish worldwide (Eissa et al, 2010). Several bacteria are reported to cause infection and mortality in both fish and humans (Austin et al., 2005).

Of bacteria generally described as fish-borne zoonoses, Mycobacterium species, Streptococcus iniae, Clostridium botulinum, and Vibrio vulnificus appear to be well-supported as zoonoses in the strict sense in addition to the occurrence of human pathogenic bacteria such as Salmonella typhi, Pseudomonas aeruginosa, Escherichia coli, Staphylococcus aureus, and Enterococcus faecalis from edible fish and water samples. Edwardsiella tarda (E. tarda) causes a disease commonly known as fish gangrene which is emphysematous putrefactive disease. It occurs sporadically in both fish and humans. It causes severe economic losses in fish in many countries (David, 2015).

\section{CONCLUSION AND RECOMMENDATIONS}

Most outbreaks of food poisoning associated with fish derive from the consumption of raw or insufficiently heat treated fish, which may be contaminated with bacteria from water environment (Vibrio spp., C. botulinum) or terrestrial sources (C. perfringens, Salmonella spp., Shigella spp., Staphylococcus spp., V.cholerae), or fish products recontaminated after heat processing. Wound infections, caused particularly by mycobacteria, St. iniae, Erys. rhusiopathiae or $P h$. damselae and $V$. alginolyticus are seen after injury during handling fish or after exposure of open wounds to water environment. In the case of poor hygiene, the contamination of fish and fish products may increase due to unsanitary procedures, the rotation of the assigned duties of workers, and airborne microorganisms during packing of the product.

Therefore, the following recommendations are forwarded:-

- Communication and medical diagnostics should be improved to control topically acquired infections from aquatic animals.

- Awareness should be created for fishermen and communities on the different types of bacterial zoonoses and their mode of transmission.

- Hygienic handling procedure should be in place during processing of fish.

- Eating of raw and undercooked fish meat should be avoided to prevent zoonoses

\section{REFERENCES}

[1] Aschfalk A. and Muller W. (2002): Clostridium perfringens toxin types from wild-caught Atlantic cod (Gadusmorhua L.), determined by PCR and ELISA. Can. J.Microbiol., 48, 365368.

[2] Austin B, Austin D, Sutherland R, Thompson F and Swings J. (2005): Pathogenicity of Vibrios to rainbow trout (Oncorhynchus mykiss, Walbaum) and Artemia nauplii. Environ. Microbiol., 7(9):1488-1495.

[3] Austin B, Austin D, Sutherland R, Thompson F and Swings J. (2005): Pathogenicity of Vibrios to rainbow trout (Oncorhynchus mykiss, Walbaum) and Artemia nauplii. Environ. Microbiol; 7(9):1488-1495.

[4] Austin B. (2010): Vibrios as causal agents of zoonoses. Vet. Microbiol., 140 (3-4), 310-317.

[5] Austin B. and Austin D.A. (2007): Bacterial fish pathogens: disease of farmed and wild fish, 4th Ed. Springer Praxis Publishing, Chichester, United Kingdom, pp 552.

[6] Baffone W., Pianetti A., Bruscolini F., Barbieri E., Citterio B. (2000): Occurrence and expression of virulence-related properties of Vibrio species isolated from widely consumed seafood products. Int. J. Food Microbiol., 54,918 . 
[7] Baiano, J.C.F.and Barnes A.C. (2009): Towards control of Streptococcus iniae. Emerg.infect.Dis., 15 (12), 1891-1896.

[8] Borenstein M. and Kerdel F. (2003): Infections with Vibriovulnificus. Dermatol. Clin., 21, 245-248.

[9] Bowden T, Bricknell L, Ellis AE (2003): Fish vaccination, an overview. Report (2003):5-20

[10] Chattopadhyay P. (2000): Fish catching and handling. In: Robinson R.K. (ed.): Encyclopedia of Food Microbiology.Vol. 2, Academic Press, London. pp.1547

[11] Chiang S.R. and Chuang Y.C. (2003): Vibrio vulnificusinfection: clinical manifestations, pathogenesis, and antimicrobial therapy. $J$. Microbiol. Immunol. Infect. 36, 81-88.

[12] David TG. (2015): Bacterial zoonoses of fishes: A review and appraisal of evidence for linkages between fish and human infections. The Veterinary Journal. 203(1):27-35.

[13] Diamant A., Banet A., Ucko M., Colorni A., Knibb W. and Kvitt H. (2000): Mycobacteriosis in wild rabbit fish Siganus rivulatus associated with cage farming in the Gulf of Eilat, Red Sea. Dis. Aquat. Organ., 39, 211-219.

[14] Eissa NM, ElGhiet EN, Shaheen A, Abbas A (2010): Characterization of Pseudomona species isolated from Tilapia (Oreochromis niloticus) in Qaroun and Wadi-El-Rayan lakes, Egypt. Global Veterinaria. 5:116-121.

[15] Evans J.J., Klesius P.H., Haenen O. and Shoemaker C.A. (2009): Overview of zoonotic infections from fish and shellfish. Zoonotic infections from fish and shellfish. In Program, abstracts and report of European Association of Fish Pathologists (EAFP) Workshop. Proc. EAFP International Conference, 14-19 September, Prague, Czech Republic, pp 6. Available at: www.docstoc.com/docs/23129401/.

[16] Evans J.J., Klesius P.H., Plumb J.A. and Shoemaker C.A. (2011): Edwardsiella septicaemias. In Fish diseases and disorders: viral, bacterial and fungal infections (P.T.K. Woo \& D.W. Bruno, eds), 2nd Ed, Vol. III. $\mathrm{CAB}$ International, Wallingford, United Kingdom, 512-569.

[17] Feingold M.H., Kumar M.L. (2004): Otitis media associated with Vibrio alginolyticus in a child with pressure equalizing tubes. Pediatr. Infect. Dis. J., 23, 475-476.

[18] Food and Agriculture Organization of the United Nations (FAO) (2012): The state of world fisheries and aquaculture, 2012. FAO, Rome.

[19] Fouz B., Larsen J.L. \& Amaro C. (2006): Vibrio vulnificus serovar A: an emerging pathogen in European anguilliculture. J. Fish Dis., 29, 285-291.
[20] Haenen O., Evans J.J. and Berthe F. (2013): Bacterial infections from aquatic species: potential for and prevention of contact zoonoses. Rev. sci. tech. Off. int. Epiz., 2013, 32 (2), 497-507.

[21] Ho MH, Ho CK and Chong LY. (2006): Atypical mycobacterial cutaneous infections in Hong Kong: 10-year retrospective study. Hong Kong Med J 2006; 12:21-26.

[22] Huss H.H., Ababouch L. and Gram L. (2003): Assessment and management of sea food safety and quality. FAO Fisheries Technical Paper 444. FAO, Rome.

[23] Iwamoto M, Ayers T, Mahon BE and Swerdlow DL. (2010): Epidemiology of seafood-associated infections in the United States. Clin Microbiol Rev; 23:399-411.

[24] Jacobs J.M., Stine C.B., Baya A.M. and Kent M.L. (2009): A review of mycobacteriosis in marine fish. J. Fish Dis., 32, 119-130.

[25] Jahncke ML and Schwarz MH (2002): Public, animal and environmental aquaculture health issues in industrial countries. In: Jahncke M, Garrett ES, Reilly A, et al, eds. Public, animal, and environmentalaquaculture health issues. New York: John Wiley \& Sons; 67-102.

[26] Kebede B and Habtamu T. (2016): Isolation and Identification of Edwardsiella tarda from Lake Zeway and Langano, Southern Oromia, Ethiopia. Fish Aqua J. 2016; 7(4):184.

[27] Lehane L. and Rawlin G.T. (2000): Topically acquired bacterial zoonoses from fish: a review. Med. J. Aust., 173, 256-259.

[28] Leon C. and Kaya. (2014): The important bacterial zoonoses in "One Health" concept.

[29] Longo, Dan, et al. (2011): Harrison's Principles of Internal Medicine 18th edition. McGraw-Hill Professional, 2011

[30] Mekonnen Sorsa, Gezahegne Mamo and Lemma Abera (2019): Major fish-borne bacteria and parasitic zoonoses in Ethiopia. International Journal of Fauna and Biological Studies; 6(4): 50-58.

[31] Midlyng, P., Bleie, H., Helgason, S., Janson, E., Larsen, J.L., Olesen, N.J., Olsen, A.B. and Vennerstrøm, P. (2000): Nordic manual for the surveillance and diagnosis of infectious diseases in farmed salmonids. Copenhagen, Nordic Council of Ministers. pp.100

[32] Nemetz $T$ and Shotts E. (1993): Zoonotic diseases In: Fish medicine. Philadelphia: WB Saunders Co, 1993; 214-220.

[33] Niamah AK. (2012): Detected of aero gene in Aeromonas hydrophila isolates from shrimp and peeled shrimp samples in local markets. $J$ Microb. Biot. and Food Sci. 2012; 2 (2):634639. 
[34] Noga E (2010): Post mortem techniques. In: Noga E, editor. Fish disease, diagnosis and treatment. 2nd edition. Ames (IA): Iowa State University Press; 2010. p. 1923.

[35] NORM/NORM-VET. (2010): Usage of Antimicrobial Agents and Occurrence of Antimi- crobia lResistancein Norway. Troms $\emptyset$.

[36] Normanno G., Parisi A., Addante N., Quaglia N.C., Dambrosio A., Montagna C. and Chiocco D. (2006): Vibrioparahaemolyticus, Vibrio vulnificus and microorganisms of fecal origin in mussels (Mytilus galloprovincialis) sold in the Puglia region (Italy). Int. J. Food Microbiol., 106 (2), 219-222.

[37] Novotny L., Dvorska L., Lorencova A., Veran V. and Pavlik I. (2004): Fish: a potential source of bacterial pathogens for human beings. Vet. Med. Czech, 49(9): 343-358.

[38] Nuru A. (2007): Study on bacterial pathogens of fish in Southern Gulf ofLake Tana with special references to Aeromonas hydrophila andEdwardsiella tarda. Debere Zeit, Ethiopia: Addis Ababa University. FVMpp: 10-30.

[39] Oliver JD (2005): Wound infections caused by Vibrio vulnificus and other marine bacteria. Epidemiol Infect., 133:383-391.

[40] Osawa M., Tachibana M., Arita M., Hashimoto T., IshidaT., Hongo T. and Fujii H. (2002): An autopsied case of septicemia due to Vibrio vulnificus. Kansenshogaku Zasshi.,76, 63-66.

[41] Plumb, J.A. and Hanson, L.A. (2011): Health Maintenance and Principal Microbial Diseases of Cultured Fishes. Wiley-Blackwell, Ames, Iowa, USA.

[42] Qu F., Cui E.B., Xia G.M., He J.Y., Hong W., Li B. and MaoY.L. (2003): The clinical features and prognosis of Aeromonas septicaemia in hepatic cirrhosis: a report of 50 cases (in Chinese). Zhonghua Nei Ke Za Zhi., 42,840-842.

[43] Ravel A, Greig J, Tinga C, et al. (2009): Exploring historical Canadian foodborne outbreak data sets for human illness attribution. J Food Prot., 72:1963-1976.

[44] Reilly, G D; Reilly, C A; Smith, E G; BakerAustin, C (2011): "Vibrio alginolyticusassociated wound infection acquired in British waters, Guernsey, July 2011". Euro Surveill. 16 (42).

[45] Savan, R., Igarashi, A., Matsuoka, S., and M. Sakai. (2004): Sensitive and Rapid Detection of Edwardsiellosis in Fish by a Loop-mediated Isothermal Amplification Method. Appl. Environ. Microbiol. 70(1):621-4.
[46] Senanayake SN, Ferson MJ, Botham SJ, et al. (2004): A child with Salmonella enterica serotype Paratyphi B infection acquired from a fish tank. Med J Aust., 180:250.

[47] Shiina Y., Ii K., Iwanaga M. (2004): An Aeromonas veroniibiovar Sobria infection with disseminated intravasculargas production. $J$. Infect. Chemother., 10, 37-41.

[48] Snježana Z. and Vladimir R. (2017): West Balkans Regional Aquatic Animal Disease Diagnostic Manual. Food and Agriculture Organization of the United Nations Rome.

[49] Swain, P., and S.K. Nayak. (2003): Comparative sensitivity of different serological tests for sero monitoring and surveillance of Edwardsiella tarda infection of Indian major carps. Fish Shell fish Immunol. 15(4):333-40.

[50] Teka W, Nolkes D, Getachew Y and Mulachew M. (2017): Microbiological quality of frozen raw and undercooked Nile tilapia (Oreochromis niloticus) fillets and food safety practices of fish handlers in Arba Minch town, SNNPR, Ethiopia. J Vet. Med. Anim. Health.

[51] Toby, L. and Stephen, A. (2007): Aquatic zoonoses associated with food, bait, ornamental, and tropical fish. JAVMA, Vol 231, No. 6, September 15, 2007.

[52] Todar K. (2008): Vibrio vulnificus. Available at: www.textbookof bacteriology. net/ V.vulnificus. html

[53] Toranzo AE, Magarinos B and Romalde JL. (2005): A Review of the Main Bacterial. Agriculture. 246:37-61.

[54] Tsfaye S, Kasye M, Chane M, Bogale B and Abebeagre Z (2018): Preliminary Survey of Gram Negative Bacterial Pathogens from Commonly Caught Fish Species (Oreochromis niloticus, Cyprinus carpio and Clarias gariepinus) in Lake Hayiq, Ethiopia. Fish Aqua J 9: 238. doi:10.4172/2150-3508.1000238.

[55] Verner-Jeffreys D.W., Baker-Austin C., Pond M.J., Rimmer G.S.E., Kerr R., Stone D., Griffin R., White P., Stinton N., Denham K., Leigh J., Jones N., Longshaw M. and Feist S.W. (2012): Zoonotic disease pathogens in fish used for pedicure letter. Emerg. infect. Dis., 18 (6).

[56] Wei Q. (2002): Social and economic impacts of aquatic animal health problems in aquaculture in China. FAO Fisheries Technical Paper 2002; 406:55-61.

[57] Yousr AH, Napis S, Rusul GR and Son R (2007): Detection of Aerolysin and Hemolysin Genes in Aeromonas spp. Isolated from Environmental and Shellfish Sources by Polymerase Chain Reaction. Asian Food Journal. 14 (2):115-122. 